\title{
Cardiac surgery residency and transcatheter aortic valve replacement: "What happened to my aortic valve replacement?"
}

\author{
Ali Hage, MD, Fadi Hage, MD, and Michael W. A. Chu, MD, FRCSC
}

\footnotetext{
From the Division of Cardiac Surgery, Department of Surgery, Western University, Lawson Health Research Institute, London, Ontario, Canada.

Disclosures: Dr Michael W. A. Chu holds proctorships and receives speaker's honoraria from Medtronic (Dublin, Ireland) and Boston Scientific (Boston, Mass) and receives speaker's honoraria from Abbott Vascular (Santa Clara, Calif) and Terumo Aortic (Glasgow, UK). All other authors have nothing to disclose with regard to commercial support.

Drs Ali Hage and Fadi Hage contributed equally to this work and are co-first authors.

Received for publication Feb 5, 2019; revisions received March 25, 2019; accepted for publication March 27, 2019; available ahead of print April 30, 2019.

Address for reprints: Michael W. A. Chu, MD, FRCSC, London Health Sciences Centre, 339 Windermere Rd, B6106, University Hospital, London, Ontario, Canada N6A 5A5 (E-mail: Michael.Chu@1hsc.on.ca).

J Thorac Cardiovasc Surg 2020;159:215-7

$0022-5223 / \$ 36.00$

Copyright (C) 2019 by The American Association for Thoracic Surgery

https://doi.org/10.1016/j.jtcvs.2019.03.059
}

Contemporary cardiac surgery has evolved significantly in the last decade. In fact, minimally invasive cardiac procedures, along with transcatheter interventions, have become a standard of care in various clinical settings. ${ }^{1}$ Today's patient is always looking for a less invasive procedure that provides the shortest hospital stay, the best cosmesis, and the least morbidity. ${ }^{2}$ As a result, these minimally invasive and transcatheter procedures have become common practice, and surgical trainees are currently exposed to them through subspecialized electives and fellowships.

Cardiac surgery residency training programs in Canada have acknowledged the rapid advancements in the minimally invasive and transcatheter fields and have adjusted accordingly. Canadian cardiac surgery residency is a 6-year, direct entry from medical school, training program with a direct focus on all aspects of cardiovascular disease. From our perspective as junior cardiac surgery residents (A.H. and F.H.), the traditional residency training could be divided into 3 levels, with few variations among the residency programs in the country. At the junior level, which spans 2 years, the residents are introduced to the fundamentals of surgery, the fundamentals of cardiology, and the basics of cardiac surgery. In addition to rotating on cardiac surgery, the junior resident gets exposed to thoracic surgery, vascular surgery, intensive care, and cardiac catheterization and cardiovascular imaging. The intermediate level (years 3 and 4) consists mainly of senior rotations in thoracic and vascular surgery, which also includes a research or academic year. Finally, in their senior years (years 5 and 6), the cardiac surgery trainees will spend most of their time in cardiac surgery. Currently, Canadian cardiac surgery training programs expose their residents to the fundamentals of cardiac surgery (such as coronary artery

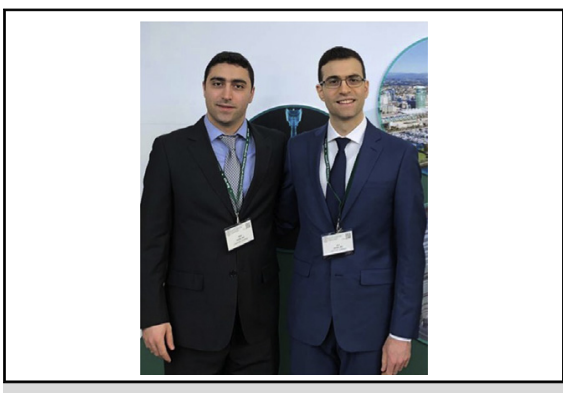

Ali Hage, MD (right), and Fadi Hage, MD (left)

\section{Central Message}

In face of the rapidly evolving field of TAVR, cardiac surgery residency should be reformed to provide trainees with sufficient tools to be experts at managing aortic valve disease in the future.

See Commentary on page 218 .

revascularization and valvular repair and replacement). In addition, most of these programs offer their residents exposure to advanced procedures, such as minimally invasive valve and coronary revascularization techniques, complex aortic and valvular surgery, ventricular and extracorporeal assistance devices, heart transplantation, and transcatheter interventions. These exposures provide the residents with a general overview of the indications and contraindications for these procedures, along with their general techniques and pitfalls. The residents rarely become technically proficient, however, in the more advanced, novel procedures, such as valve-sparing root reconstruction and complex mitral repair, to a level at which they are able to perform them safely after the completion of their residency training, without completing additional fellowships.

Although the lack of an in-depth familiarity is understandable for most of these advanced procedures, this should not be the case for the most common percutaneous intervention, transcatheter aortic valve replacement (TAVR). In fact, we believe that cardiac surgery residents should acquire a prerequisite level of "wire skills" by the end of their training and should become capable of performing a "straightforward" TAVR. In the most recent update of the guidelines for patients with valvular heart disease, 
TAVR has become recommended for an enlarging percentage of patients with aortic stenosis, ${ }^{3}$ and it is undoubtfully expected to change our practice in the very near future with the recent publication of the low-risk TAVR trials in The New England Journal of Medicine. ${ }^{4,5}$ Moreover, at the same time, percutaneous mitral and tricuspid interventions are also rapidly evolving and will become part of the standard of care in the near future. ${ }^{6}$ Cardiac surgery residents therefore must attain basic competencies with wire skills to be ready for what the future of the specialty unquestionably holds for them.

\section{WHAT SHOULD BE DONE?}

To attain sufficient exposure, cardiac surgery residents must actively participate in various transcatheter procedures during the course of their residency training. First, the residents should be exposed, from an early point, to central arterial and venous line insertion, intra-aortic balloon pump insertion, and diagnostic coronary angiography (as well as percutaneous coronary interventions). They should become familiar with managing both mobile and fixed fluoroscopes and with the hazards of radiation exposure. Development of a core knowledge and understanding of wirebased skills and catheter management is paramount. In addition, residents should be strongly encouraged to include additional rotations in percutaneous interventions with interventional radiology and vascular surgery, where they will be involved in thoracic endovascular aneurysm repair, or subspecialized cardiac practices including MitraClip (Abbott Vascular, Santa Clara, Calif) and other novel transcatheter mitral technologies. The resident trainees should be supported to attend the various percutaneous boot camps or transcatheter training opportunities that are often offered at international cardiovascular and thoracic annual meetings. In addition to these percutaneous boot camps, many companies (such as Edwards Lifesciences, Irvine, Calif, and Medtronic, Dublin, Ireland) are eager to set up wet labs for resident education. More importantly, the use of these to train interventional cardiology residents in combined wet labs is another way for the programs to integrate and work closely together in a positive way.

At the same time, the residents must attend multidisciplinary TAVR rounds that take place regularly at most large tertiary cardiac centers. During these meetings, the surgical trainees become more familiar with the processes of patient selection, valve selection, and access selection, along with the indications and contraindications for TAVR. In addition, surgical residents have to become integrated into TAVR rounds in an equal fashion to cardiology trainees. Examples of such integration include copresenting case reports at the multidisciplinary meetings and seeing TAVR consults and follow-ups in a shared, alternating fashion.

In terms of the actual operative technical exposure, the residents should display the same level of discipline and motivation as they usually do when participating in a standard cardiac surgical procedure, such as a conventional aortic valve replacement. Preoperatively, the residents must carefully review the imaging studies that have been performed, which include (1) echocardiography to assess valve morphology and function and (2) computed tomographic scan to understand valve sizing, to anticipate left ventricular outflow tract and aortic root hazards, and to assess optimal transcatheter access routes. In the hybrid operating room or catheterization laboratory, the residents should become acquainted with the various tools and instruments that are being used, which include multiple wires, sheaths, delivery devices, and valves. The surgical trainees should be exposed to the several techniques of transcatheter access (transfemoral, transapical, transcarotid, direct aortic, and subclavian) as well. Thereafter, as the residents advance through their residency training, they would gradually become more comfortable with the various steps and techniques.

Although the residents are the ones most responsible for the quality of their training, ensuring that residents get adequate exposure to wire skills is also the responsibility of the residency program directors and the oversight associations. Currently, the residency training in Canada is transitioning to "Competence by Design," a form of competency-based medical education in which residents are expected to achieve a certain number of standardized entrustable professional activities and their related milestones before the completion of their training. Similar to how the American Board of Thoracic Surgery has added "interventional skills and procedures" to its certification requirements, the Royal College of Physicians and Surgeons of Canada has specifically included, in its most recent update (2019, version 1.0), "cardiac catheterization laboratory" and "endovascular surgery" as required training experiences. ${ }^{7}$ This is consistent with the previous training requirements outlined in the 2013 (version 1.0) objectives of training, in which knowledge and skills were required for "alternative surgical approaches to cardiac valves (including Transcatheter Aortic-Valve Implantation)."

\section{A WORD OF ADVICE}

Although the fundamental concept of a heart team allows the cardiac surgeon to be actively involved with the cardiologist in selecting the best intervention modality for the patient, it is unfortunate that in some institutions there remain hostile relationships between cardiology and cardiac surgery. ${ }^{9}$ Despite this, cardiac surgery trainees should attempt to be treated similarly to the cardiology trainees to maximize their educational opportunities. In fact, to ensure that we, as future cardiac surgeons, continue to be experts in aortic valve disease, TAVR should become an integrated part of our residency training, and we should be exposed to it to the same degree as we currently are for conventional 
aortic valve replacement. This goes without saying for the other transcatheter therapies as well, including those designed to address the mitral valve (repair and replacement) and pulmonary valve, and also for left ventricular assist devices. In a recent Canadian survey by Juanda and colleagues,${ }^{10}$ looking at the experience of current Canadian cardiac surgery residents and recent graduates in terms of their exposure to catheter-based therapies, more than a third of the responders reported facing resistance from nonsurgical trainees who were competing for the same rotations. In addition, a substantial number of the responders had their rotations denied. Despite these obstacles, the vast majority of the responders recognized the vital necessity to get adequate exposure to wire skills because of the substantial role that hybrid and catheter-based procedures are currently taking and will continue to take in the future. ${ }^{10}$

We also acknowledge that "exposure" is not "competency"; however, we strongly believe that exposure is the first and most important step to eventually becoming competent with these technologies. This was clearly reflected in the survey by Juanda and colleagues,${ }^{10}$ in which most cardiac surgery trainees believed that being the main operator during diagnostic catheterization procedures was significantly associated with the sense of being able to perform the technique independently.

In another recent survey by Tam and colleagues ${ }^{11}$ that investigated the current experience of Canadian cardiac surgery residents with TAVR training, only $18 \%$ of residents felt that their current training with TAVR was adequate. Although more than $90 \%$ of residents and program directors believed that TAVR is an integrated part of the future of the specialty, less than a third of the residency programs reported having access to TAVR training facilities. In addition, multiple barriers to TAVR training were reported, and these included the absence of dedicated time during residency, competition with TAVR fellows, and a belief that interventional cardiologists were not interested in training surgical residents. ${ }^{11}$

In the famous book "Who Moved My Cheese? An Amazing Way to Deal with Change in Your Work and in Your Life," ${ }^{12}$ Dr Spencer Johnson recounts the story of 4 mice living in a maze and adapting to a shrinkage in their cheese supply. Two of the mice adapted rapidly and discovered innovative ways to find a new stock. The other 2 mice were stubborn, however, and did not believe that a change in their supply could possibly occur. When the cheese was gone, these 2 mice confusedly wondered: "Who moved my cheese?" Despite later changing their behavior and eventually finding a new source of cheese, they never reached the same amount of wealth that they initially had.

As cardiac surgery residents and future cardiac surgeons, let us rapidly reform our surgical training in the fastevolving field of TAVR, and let us never ask "Who moved my aortic valve?'

\section{References}

1. Iribarne A, Easterwood R, Chan EY, Yang J, Soni L, Russo MJ, et al. The golden age of minimally invasive cardiothoracic surgery: current and future perspectives. Future Cardiol. 2011;7:333-46.

2. Ghoneim A, Bouhout I, Makhdom F, Chu MW. Mitral repair and the robot: a revolutionary tool or marketing ploy? Curr Opin Cardiol. 2018;33:148-54.

3. Nishimura RA, Otto CM, Bonow RO, Carabello BA, Erwin JP III, Fleisher LA, et al. 2017 AHA/ACC focused update of the 2014 AHA/ACC guideline for the management of patients with valvular heart disease: a report of the American College of Cardiology/American Heart Association task force on clinical practice guidelines. J Am Coll Cardiol. 2017;70:252-89.

4. Popma JJ, Deeb GM, Yakubov SJ, Mumtaz M, Gada H, O'Hair D, et al. Transcatheter aortic-valve replacement with a self-expanding valve in low-risk patients. N Engl J Med. 2019;380:1706-15.

5. Mack MJ, Leon MB, Thourani VH, Makkar R, Kodali SK, Russo M, et al. Transcatheter aortic-valve replacement with a balloon-expandable valve in low-risk patients. N Engl J Med. 2019;381:682-5.

6. Stone GW, Lindenfeld J, Abraham WT, Kar S, Lim DS, Mishell JM, et al. Transcatheter mitral-valve repair in patients with heart failure. N Engl J Med. 2018; 379:2307-18.

7. The Royal College of Physicians and Surgeons of Canada. 2017. Available at: http://www.royalcollege.ca/rcsite/documents/ibd/cardiac-surgery-rte-trainingexperiences-e.pdf. Accessed April 23, 2019.

8. The Royal College of Physicians and Surgeons of Canada. 2013. Available at: www.royalcollege.ca/rcsite/documents/ibd/cardiac_surgery_otr_e.pdf. Accessed April 23, 2019.

9. Yadava OP. "Heart team" concept—a reality or a "platonic illusion". Indian Heart J. 2017;69:681-3.

10. Juanda N, Chan V, Chan R, Rubens FD. Catheter-based educational experiences: a Canadian survey of current residents and recent graduates in cardiac surgery. Can J Cardiol. 2016;32:391-4.

11. Tam DY, Makhdoum A, Ouzounian M, Wijeysundera HC, Cohen GN Fremes SE. The state of transcatheter aortic valve implantation training in Canadian cardiac surgery residency programs. Can J Surg. 2018;61:418.

12. Johnson S. Who Moved My Cheese?: An Amazing Way to Deal with Change in Your Work and in Your Life. Part 1: Changing the Way You Look at Change. New York: Putnam; 1998. DVD. 